\title{
Vínculo familiar na atenção Psicossocial a adolescentes do CAPSI
}

\author{
Nicácia Souza Oliveira ${ }^{1}$; Alana Barbosa Lima ${ }^{2}$; Francisca Silva de Alencar ${ }^{3}$; Gisele Lopes Oliveira ${ }^{4}$; \\ Lúcia Vanda Teixeira de Freitas ${ }^{5}$; Ana Verônica Alencar ${ }^{6}$; Gislene Farias de Oliveira ${ }^{7}$
}

\begin{abstract}
Resumo: A família é responsável pela procriação, formação e socialização dos seus integrantes. A interação entre familiares e equipe multidisciplinar, dá continuidade e maiores chances de resolutividade ao trabalho desenvolvido com os adolescentes, pelos profissionais de saúde mental do CAPSi. Essa pesquisa tem como objetivo geral, conhecer a importância do vinculo familiar junto ao tratamento e reabilitação de adolescentes clientes do CAPSi do município de Iguatu-Ce. Trata-se de um estudo descritivo, exploratório, com abordagem qualitativa e realizado em campo. Utilizou-se uma entrevista semi-estruturada com 10 adultos familiares dos adolescentes assistidos pelo CAPSi, durante o mês de janeiro de 2013. Posteriormente, os dados foram apresentados em categorias e analisados através da técnica da análise de conteúdo. De acordo com os resultados da pesquisa, constatou-se que a maioria das participantes tinha acima de 50 anos, todas eram do sexo feminino, casadas, a maioria eram as próprias mães dos adolescentes, possuíam baixo grau de escolaridade e renda familiar de apenas um salário mínimo. Foi notório que a maior parte das entrevistadas não reagiu bem ao ter conhecimento de que o filho necessitaria realizar tratamento no CAPSi e que cuidar desses adolescentes é uma função muito difícil e desgastante. Observou-se também que os familiares mostraram-se satisfeitos quanto ao acolhimento por parte dos profissionais de saúde mental da instituição. Dessa forma, conclui-se que a interação da família com a equipe multiprofissional é de extrema importância durante o processo de reabilitação de adolescentes psiquicamente afetados.
\end{abstract}

Palavras-chave: Saúde mental, Família, Adolescentes, Atenção Psicossocial.

\section{Family Bonding in Psychosocial Care of Adolescents assisted by CAPSI}

\begin{abstract}
The family is responsible for breeding, training and socialization of its members. Knowing that the interaction between family and multidisciplinary team provides continuity and greater chances of solving to work with adolescents by mental health professionals in CAPSi. This research aims to generally know the importance of the family bond with the treatment and rehabilitation of adolescent clients CAPSi the city of Iguatu-Ce. This is a descriptive, exploratory study with a qualitative approach and conducted in the field. We used a semi-structured interviews with 10 adult relatives of adolescents assisted by CAPSi during the month of January 2013. Subsequently, the data were presented in categories and analyzed using the technique of content analysis. According to the survey results, it was found that most participants were older than 50 years, all were female, married, most were their own mothers had low education level, and family income only a salary minimum. It was apparent that most of the respondents did not react well to be aware that the child would need to perform CAPSi treatment and care for these adolescents is a very difficult and stressful function. It was also observed that the relatives were satisfied as to the reception on the part of mental health professionals of the institution. Thus, it is concluded that the interaction of the family with a multidisciplinary team is of paramount importance during the process of rehabilitation of affected adolescents psychically.
\end{abstract}

Keywords: Mental Health, Family, Adolescents, Psychosocial Care.

\footnotetext{
${ }^{1}$ Professora da Universidade Regional do Cariri-URCA/UDI. E-mail: nicaciaoliveira@hotmail.com

${ }^{2}$ Enfermeira pela Universidade Regional do Cariri-URCA/UDI.E-mail allanalymaenf@ @ hotmail.com

${ }^{3}$ Enfermeira pela Universidade Regional do Cariri - URCA, Especialista em Saúde da Família pela Faculdade São Francisco da Paraíba -

FASP, Professora da Faculdade Vale do salgado - FVS. E-mail:silvia.rami@ hotmail.com

${ }^{4}$ Enfermeira. Professora da Universidade Regional do Cariri-URCA/UDI. E-mail: giselelopes 4@hotmail.com

${ }^{5}$ Enfermeira. Professora da Universidade Regional do Cariri-URCA/UDI. Email: lvtfreitas@ yahoo.com.br

${ }^{6}$ Psicóloga pela Universidade Estadual da Paraíba (UEPB). E-mail: veronicauepb@yahoo.com.br

${ }^{7}$ Psicóloga e Professora da Universidade Federal do Cariri, Ceará, Brasil. E-mail: gislenefarias@gmail.com
} 


\section{Introdução}

Em 1989, o deputado Paulo Delgado instituiu a Lei da Reforma Psiquiátrica (Lei n ${ }^{\circ}$ 10. 216, de abril de 2001) que dispôs sobre a proteção e os direitos das pessoas portadoras de transtornos mentais e direcionou o modelo assistencial em saúde mental, regulamentando o cuidado especial com a clientela internada por longos anos e prevendo a possibilidade de punição para a internação involuntária, arbitrária e/ ou desnecessária (BRASIL, 2004).

Após várias discussões foram estabelecidos serviços para que a população não ficasse desassistida. Criaram-se então, os lares abrigos, os atendimentos ambulatoriais, os Núcleos de Atenção Psicossocial (NAPS), os Centros de Atenção psicossocial (CAPS) e os hospitais dia e os hospitais noite (SAMPAIO, 2008).

De acordo com a portaria GM 336/2002, os Centros de Atenção Psicossociais para a Infância e Adolescência (CAPSi) são serviços de base territorial e são responsáveis pelo acesso de crianças e adolescentes com transtornos mentais ao cuidado integral, conforme suas necessidades e de sua família. Cabe aos CAPSi organizar a rede de cuidados, integrando os diversos instrumentos de apoio social, em especial, as famílias (REIS et al. 2010).

O sofrimento psíquico de crianças e adolescentes têm números crescentes na sociedade. No Brasil, aproximadamente de $10 \%$ a $20 \%$ da população de crianças e adolescentes sofrem de 'transtornos mentais' e, dessa porcentagem, de 3\% a 4\% necessitam de tratamento intensivo (BRASIL, 2005).

No antigo modelo hospitalocêntrico, afastava-se o indivíduo do seu convívio familiar com o pretexto de que ele não seria capaz de viver em sociedade. Com a Reforma Psiquiátrica, atentou-se para o valor da família ao indivíduo, sendo esta, considerada o lugar no qual, este, originou-se e acostumou-se a viver, necessitando ser respeitada. O direito a estar dentro de uma família, e ter uma convivência cotidiana com pais, irmãos e outros familiares é mais do que estar fisicamente dentro de quatro paredes de uma habitação. Inclui poder ultrapassar essas paredes como um pequeno cidadão, protegido e orientado, para ser incluído na linguagem, nos valores e nas formas de agir que vão aos poucos sendo reconhecidos como aqueles que compõem "sua" cultura e lhe atribui identidade social. A família é uma passagem para o mundo. Estar dentro de uma família, além da casa, é estar no âmago de um mundo a se conhecer e se apropriar a partir dos direitos de cidadania (BRASIL, 2005).

$\mathrm{O}$ interesse pelo assunto nasceu durante o $5^{\circ}$ semestre da faculdade, ao estudar a cadeira de saúde mental. Sendo assim, a escolha do tema justifica-se pelo anseio de estabelecer a importância do vínculo familiar na atenção psicossocial de adolescentes portadores de transtornos mentais

Id en line Revista de Psicologia. Ano 8, No. 22, Fevereiro/2014 - ISSN 1981-1179. Edição eletrônica em http://idonline.emnuvens.com.br/id 
Diante disso, há o surgimento de alguns questionamentos: será que a família compreende sua importância junto ao tratamento e recuperação dos adolescentes com transtornos mentais? Qual a real relação existente entre a equipe de saúde e os familiares? Como se deu o apoio familiar para com o adolescente, após a descoberta de seu sofrimento psíquico?

Sabendo-se, que a interação entre família e equipe multidisciplinar dá continuidade e maiores chances de resolutividade ao trabalho desenvolvido com os adolescentes pelos profissionais de saúde mental no CAPSi, tem-se contudo, como relevância dessa pesquisa, mostrar, sobretudo, a importância que tem a família junto ao tratamento psiquiátrico de um ente querido e como a equipe de saúde do CAPSi pode, e deve, se posicionar. Através desse estudo poderemos também descrever de forma clara e objetiva, a real função do CAPSi, seu funcionamento, e as políticas embasadoras desse projeto.

A família que busca atendimento encontra-se, muitas vezes, angustiada e à procura de apoio para superar os problemas que estão sendo enfrentados no momento. Sendo assim, é essencial que a família sinta-se acolhida pelos profissionais do serviço.

Tendo por bases esses pensamentos, pode-se então, identificar na família, as muitas causas e/ou permanência de vários problemas psicológicos em adolescentes. A importância de se manter o vínculo família- equipe de saúde é de extrema importância para uma então conclusão dos problemas mentais.

Espera-se que o estudo e aprofundamento nesse assunto sejam de imensa valia na construção literária, acadêmica, e profissional dos estudantes de enfermagem, sobretudo dos acadêmicos da Universidade Regional do Cariri, localizada no município de Iguatu.

Esta visão sobre a família, como parceiros e corresponsáveis pelo cuidado, mostra uma postura coerente com a proposta de produção de um cuidado integral, onde o indivíduo se expressa pelo seu grupo imediato, e permite trocas e experiências com os elementos do meio onde se insere (SILVA, 2012).

Partindo dessas considerações, o objetivo do presente estudo foi conhecer a participação da família no tratamento de adolescentes assistidos pelo CAPSi. Para isso, se fez necessário também: a) Investigar a reação do familiar cuidador ao saber da necessidade do adolescente realizar tratamento no CAPSi; b) Verificar a existência de vinculo familiar junto ao cuidar do adolescente com transtorno mental; c) Identificar a visão da família a respeito das estratégias de cuidado da equipe multidisciplinar aos adolescentes clientes do CAPSi; d) Analisar as relações existentes entre a equipe de saúde mental do CAPSi e familiares. 


\section{O modelo assistencial do CAPSi}

A construção dos CAPS para crianças e adolescentes tem sua história bastante semelhante com a evolução histórica dos CAPS adultos, pois as crianças autistas e psicóticas, também eram submetidas ao modelo asilar (PINTO, 2007).

De modo geral, as políticas de saúde mental existentes estavam relacionadas aos problemas da população adulta. Para os adolescentes, os tipos de transtornos, principais fatores de risco e de proteção, estratégias de intervenção e organização do sistema de serviços tinham especificidades que não podiam ser contempladas pela simples extensão das estratégias de cuidado da população adulta à população infantil e juvenil (PATEL, 2007). Tais especificidades passavam a requerer, assim, uma política específica. A inexistência de políticas de saúde mental para esses sujeitos em quase todas as partes do mundo tornava o desenvolvimento de políticas nacionais de saúde mental não apenas necessário, como urgente (BELFER, 2008).

O destino dos adolescentes muitas vezes era a Fundação Estadual do Bem-Estar do Menor (FEBEM), ou os antes chamados juizados de menores, para as alas de manicômios ou para instituições semelhantes aos próprios hospícios (FERREIRA, 2004).

A atenção a Saúde Mental na Infância e Adolescência era realizada através de um antigo serviço ambulatorial infanto-juvenil, o Centro de Orientação da Infância e Adolescência (COIA). Tal serviço mantinha-se como referência para o tratamento psiquiátrico de crianças e adolescentes. A complexidade exigida para tais ações impulsionou a necessidade da criação de um serviço com atendimento não somente ambulatorial, mas também, intensivo. A transformação do serviço constituiu-se na criação do CAPSi Eliza Santa-Roza, localizado na cidade de São Paulo. (SAMPAIO, 2008)

O CAPSi Eliza Santa-Roza foi idealizado a partir da necessidade de que crianças e adolescentes psicóticos, autistas e neuróticos graves do território, pudessem ser atendidos num espaço de tempo maior do que o oferecido pelo ambulatório (COIA), pois eram casos que exigiam uma atenção contínua, com uma frequência maior que a oferecida pelos consultórios do serviço público de saúde (PINTO, 2007).

Segundo o autor supracitado, o ano de 1999 marcou a inauguração de um novo compromisso com o campo da infância e adolescência no que diz respeito ao atendimento das crianças e adolescentes com graves transtornos com o autismo e a psicose. Estas crianças passaram a ter prioridade em seus atendimentos.

O CAPSi foi inaugurado em dezembro de 2001, após a III Conferência Nacional de Saúde Mental. A proposta multidisciplinar de atendimento (equipe multiprofissional) e também de elementos 
de uma prática psicanalítica foi constituída e idealizada para priorizar também os projetos de desospitalização e desinstitucionalização na infância e adolescência (PINTO, 2007).

Os pacientes que podem ser acompanhados pela unidade são as crianças institucionalizadas por longos anos, pacientes de difícil condução terapêutica nas clínicas tradicionais, casos encaminhados pela rede (escolar, conselhos tutelares, lares, abrigos, UBS) e demanda espontânea (PINTO, 2007).

As atividades desenvolvidas no CAPSi são as mesmas desenvolvidas nos outros CAPS, como atendimento individual, atendimento grupal, atendimento familiar, visita domiciliar, atividades de inserção social, oficinas terapêuticas, atividades socioculturais e esportivas. Tais atividades e práticas são direcionadas a cada tipo de faixa etária (BRASIL, 2004).

Os CAPSi devem ser compostos por equipes multiprofissionais contendo no mínimo um psiquiatra, neurologista ou pediatra com formação em saúde mental infantil, um enfermeiro, quatro profissionais de nível superior (entre: psicólogo, assistente social, terapeuta ocupacional, fonoaudiólogo, pedagogo) e cinco profissionais de nível médio. Os Centos de Atenção Psicossocial infantis devem se responsabilizar pelo atendimento regular de um número limitado de pacientes e de suas famílias, em regimes diferenciados de tratamento, segundo as necessidades de cada caso, desenvolvendo um elenco diversificado de atividades terapêuticas. Neles são prioritários os atendimentos para autistas, psicóticos e para todos aqueles cuja problemática incida diretamente em prejuízos psicossociais severos (SANTOS, 2011).

O acompanhamento das crianças e adolescentes é feito através de quatro tipos de procedimentos: o intensivo, o semi-intensivo, o não intensivo e o procedimento no período das 18 às 21 horas. São definidos segundo o Ministério da Saúde:

- Cuidados intensivos: Conjunto de atendimento diário, desenvolvido individualmente e/ou grupal, com no máximo 25 pacientes por mês.

- Semi-intensivo: Conjunto de freqüientes atendimentos, desenvolvidos individualmente e/ou grupal, com no máximo 50 pacientes por mês.

- Não intensivo: Conjunto de atendimentos quinzenais ou mensais, desenvolvido individualmente ou em grupos, com no máximo 80 pacientes por mês.

- Período das 18 às 21 horas: Conjunto de atendimento desenvolvido individualmente ou em grupo com no máximo 15 pacientes por mês (BRASIL 2004).

O sistema de financiamento do CAPSi é realizado através do pagamento de um valor por usuário atendido pelo serviço, via Autorização de Procedimento de Alta Complexidade (APAC). Este documento justifica a solicitação do procedimento perante o órgão autorizador. Deve ser preenchido pelo profissional responsável pelo paciente, em duas vias. A primeira ficará no órgão autorizador e a segunda deverá ser encaminhada para a unidade onde será realizado o procedimento (BRASIL, 2004). 
O atual cenário nacional dos CAPSi sugere, através dos indicadores disponíveis, que a expansão da rede está aquém da necessária e constitui um importante desafio a ser enfrentado. Existem atualmente 132 CAPSi em funcionamento. O parâmetro populacional estabelecido pela base normativa do Ministério da Saúde (200.000 habitantes ou mais) incide diretamente sobre 130 cidades no país, sendo 14 com mais de um milhão de habitantes, onde, certamente, e não somente nelas, o número de CAPSi deveria ser maior do que um (BRASIL, 2011; COUTO, 2008).

\section{A Família e o Adolescente com Transtorno Mental}

A família é responsável pela procriação, formação e socialização dos seus integrantes. No entanto, em situação de adoecimento mental ela necessita de uma rede social de apoio para o enfrentamento de problemas que atingem o seu bem estar. As transformações da sociedade, especialmente, com a pós-modernidade têm implicado em transformações importantes na organização e dinâmica das famílias (SILVA, 2012).

Contudo, o termo família enquadra-se também para os indivíduos que se dedicam a cuidar das necessidades de outro sem ter, necessariamente, laços sanguíneos. Esses indivíduos, mais conhecidos por cuidadores, são uma legião de conjugues, noras e genros, amigos, vizinhos, membros de entidades paroquiais e de serviços que se dispõem, sem uma formação profissional de saúde, a dar aos doentes sob sua responsabilidade os cuidados indispensáveis, tendo como sua maior arma sua disponibilidade e boa vontade (LEME, 2000).

A família, dessa forma, implica e desempenha um papel importante na provisão de cuidado informal para seus membros. Há um geral reconhecimento, hoje em dia, de que ela está no centro das funções de cuidado. A vida quotidiana doméstica é caracterizada pelo atendimento às necessidades físicas e psicológicas dos diferentes membros da família. É no seu contexto social que se salva a saúde e se lida com as doenças. A família representa, na verdade, a unidade básica de atenção à saúde (SERAPIONI, 2005).

A tarefa principal da família é "o cuidado e a proteção de seus membros", segundo Guimarães et al. (2009), que acrescenta: "a família foi uma instituição criada pelo homem que trata das relações existentes entre os semelhantes e assume variadas formas em situações e tempos diferentes".

Para Ariès (1981), a família viveu, entre os séculos XV e XVIII, uma mudança do elemento definidor de sua estrutura e função social, passando de uma ligação pela capacidade de procriação e distribuição de bens materiais para um sentimento de afeto e comprometimento com a formação e socialização dos descendentes.

Id en line Revista de Psicologia. Ano 8, No. 22, Fevereiro/2014 - ISSN 1981-1179.

Edição eletrônica em http://idonline.emnuvens.com.br/id 
A família deixou de ser apenas uma instituição do direito privado para a transmissão dos bens e do nome, e assumiu uma função moral e espiritual, passando a formar corpos e almas. Entre a geração física e a instituição jurídica existia um hiato, que a educação iria preencher (ARIÈS, 1981, p.277).

Cada membro da família tem papel e importância como em um sistema. Consequentemente, o sofrimento psíquico de um dos entes acarreta modificações para e em todos os membros do sistema familiar, cada um vivenciando-as de forma particular (TÁVORA, 2011).

Pelo exposto, observa-se que a conceituação de família obedece a um sentimento ou necessidade de continuidade, de projeção, por meio de bens materiais ou afetivos. Isso possivelmente está relacionado ao emprego de valores culturais ao longo do tempo, de modo que faz a família manter-se definida por uma dessas vias (SILVA, 2012).

A família é o melhor espaço para se conhecer os modos como as doenças acometem as pessoas, favorece a visão sobre os fenômenos naturais implicados em todas as doenças: "o lugar natural da doença é o lugar natural da vida - a família - doçura dos cuidados espontâneos, testemunho do afeto, desejo comum da cura”. É o lugar que congrega tanto as forças favoráveis à saúde, quanto àquelas desencadeadoras de doenças (FOCAULT, 1994).

Diante disso, a família é responsável pelo cuidado de seus membros em sofrimento psíquico, especialmente tratando-se de criança ou adolescente, considerando a sua fase de desenvolvimento, em que fragilidade e dependência podem estar presentes (TÁVORA, 2011).

A adolescência é caracterizada por ser um período de transição entre a puberdade e o estado adulto do desenvolvimento, tem variação nas diferentes sociedades, no reconhecimento da condição adulta que se dá o indivíduo como um fenômeno específico dentro de toda a história do desenvolvimento do ser humano. Deve ser tomada como um processo universal de troca, de desprendimento, mas que será influenciado por conotações externas peculiares de cada cultura, que a favorecerão ou a dificultarão, segundo as circunstâncias (ABERASTURY; KNOBEL, 1981).

São considerados adolescentes pela Organização Mundial da Saúde (OMS) pessoas com idade entre 10 e 19 anos de idade. No entanto, de acordo com o Estatuto da Criança e do Adolescente (ECA) a adolescência compreende a fase dos 12 aos 18 anos de idade (BRASIL, 1990).

É durante essa fase que o indivíduo se desenvolve física e emocionalmente e adota comportamentos influenciados pelo meio sócio ambiental. Isto significa que o período de vida iniciado na puberdade, e que acaba quando o jovem entra no que, culturalmente, se considera a idade adulta, é caracterizado por intensas transformações (COUTO et al., 2008; CAVALCANTE et al., 2008).

Considera-se que a adolescência não é um período estável da vida humana, mas, um processo e um desenvolvimento com importantes repercussões na formação do indivíduo; "não seria normal uma situação de plena estabilidade na adolescência” (ABERASTURY; KNOBEL, 1981). 
Como base de todo este processo existe uma circunstância especial, característica própria do processo da adolescência em si, ou seja, a situação que coloca o indivíduo a reformular os conceitos que tem de si mesmo e que o levam a abandonar sua auto-imagem infantil e projetar-se no futuro de sua vida adulta (ABERASTURY; KNOBEL, 1981).

Neste sentido, Erikson (1987), autor da teoria dos oito estágios do desenvolvimento psicossocial, considera que o período psicológico entre os 12 e os 18 anos é o mais importante na vida de um indivíduo. Nele, a transformação psíquica crucial seria adquirir um senso de identidade definida como percepção consciente de quem se é e para onde se está indo. Isso seria decorrente de um processo de observação e reflexão simultâneas, em um contexto interativo entre a pessoa e o ambiente no qual está inserida. Sendo a adolescência um período marcado por diversas mudanças físicas e psicológicas poderia assim, favorecer o desencadeamento de uma série de transtornos mentais (ZAVASCHI, 2009).

Em virtude da crise essencial da adolescência, esta idade é a mais apta para sofrer os impactos de uma realidade frustrante. Ainda vale considerar que a formação de uma identidade "normal" implica a interação com a família e a sociedade, com vistas a favorecer a experiência das escolhas, das dúvidas, do heroísmo e de outras necessidades desta fase, de forma tranquiila, com menos sofrimento. A formação da identidade dos adolescentes se dá num movimento de retorno e projeção, pois ao mesmo tempo em que retorna ao equilíbrio da infância, a realidade o impulsiona a projetar-se para o futuro - para ser adulto. Nesse processo o adolescente fica mais propenso a sofrer os impactos projetivos dos pais, irmãos e de toda sociedade, ou seja, "é um receptáculo propício para encarregar-se dos conflitos dos outros e assumir os aspectos mais doentios do meio em que vive" (ABERASTURY; KNOBEL, 1981).

A adolescência e a juventude têm sido ainda alvo preferencial de um efeito de patologização (pedagogização, psicologização, psiquiatrização), onde na maior parte das vezes o que emerge do mundo adolescente ecoa no mundo adulto como impertinência, como apatia, como doença, como delinqüência. A tematização da juventude pela ótica do "problema social", como objeto de falha, disfunção ou anomia no processo de integração social e como tema de risco para a própria continuidade social, é histórica e persistente (SCHMID, 2004).

Os problemas de saúde mental mais prevalentes na adolescência podem ser divididos em quatro grupos principais: os emocionais, os de comportamento, os de concentração e os problemas com drogas. Mais raros, porém potencialmente mais graves, são as psicoses e os problemas alimentares. As alterações do desenvolvimento, como o autismo, também mais raras começando na infância, perpetuando-se até a idade adulta. (ZAVASCHI, 2009; FLEITLICH-BILYK, 2004).

As doenças mentais tendem a ter uma duração prolongada, apresentam recidivas de manifestações agudas, e ainda carregam uma imagem de incapacitação e estigmatização impostas pela 
sociedade. Isto gera uma sobrecarga de ordem física, emocional e econômica para as famílias, implicando em alterações na dinâmica familiar, comprometendo inúmeros aspectos do viver social da família como lazer, saúde, capacidade produtiva, vida social, entre outros (CAVALHERI, 2010).

Existe uma predominância de atendimentos aos adolescentes relacionados à depressão, drogas, violência e família. E são diversos os fatores que os tornam vulneráveis: a) os individuais (sexo; idade; características psicológicas como auto-estima, autoconfiança e determinação), b) os familiares (história de problemas de saúde mental, especialmente materna; problemas de álcool/drogas; violência física, psicológica e sexual; violência entre os pais; perdas por morte; separação dos pais), c) os socioculturais (pobreza, violência no contexto social, apoio/suporte social) e d) os biológicos. Ressaltamos que o grande desafio é entender como esses fatores articulam-se entre si e engendram-se no comportamento e na saúde humana (ASSIS et al., 2009; COUTO, 2008).

A presença de um membro da família com transtorno mental exige do grupo familiar uma nova organização e ainda a aquisição de "habilidades que podem, num primeiro momento, desestruturar as atividades diárias dos familiares." No entanto, essa quebra da cotidianidade da dinâmica familiar pode ser positiva para o desenvolvimento do grupo, através de uma maior aproximação entre os familiares com maior responsabilização com a pessoa adoecida, "o familiar torna-se um parceiro da equipe de saúde para cuidar do usuário, sendo facilitador nas ações de promoção da saúde mental e de inserção do indivíduo em seu meio.” (SCRANK; OLSCHOWSKY, 2008).

Portanto, é possível e necessário um maior engajamento na implementação do processo de Reforma Psiquiátrica, com vistas a ampliação das estratégias de alcance social, que favoreçam uma mudança cultural, especialmente, em relação às famílias. Isto requer mais habilidades das equipes de saúde mental no intercâmbio com os familiares de portadores de transtornos mentais. $\mathrm{O}$ trabalho da equipe junto à família implica em ajudá-las em termos da estruturação, da sua vida cotidiana no convívio com seu familiar, dando o suporte na elaboração de estratégias de cuidado para o melhoramento de sua performance no enfrentamento do transtorno mental no contexto de vida. Isto implica "esclarecer sobre as propostas terapêuticas, compartilhar informações sobre diagnóstico, medicação, o que fazer em situação de crise, dentre outros aspectos" (DIMENSTEIN et al., 2010).

Dessa forma, as famílias necessitam do apoio de todos os agentes sociais, que formam sua rede social. Isto porque, a sociedade não dispõe de um modo geral, de serviços que dêem conta da qualidade da demanda de doentes mentais e familiares de forma efetiva (COLVERO; IDE; ROLIM, 2004).

Os profissionais que cuidam de pessoas com transtornos mentais, ainda mostram insegurança frente à individualidade desses indivíduos, uma vez que recorrem à família e/ou a outros agentes sociais para intermediar a responsabilização sobre os atos dos mesmos. Isto demonstra ainda certa 
fragilidade da relação do serviço com o usuário em si, "muitas vezes os processos de individualização acontecem via responsabilização de entes intermediários" (SILVA, 2009).

Dessa forma, faz-se necessário maior empoderamento de familiares e usuários, com vistas a uma política de valorização dos sujeitos, o que compreende mudanças na forma de gestão dos serviços e de inclusão social e reabilitação psicossocial (DIMENSTEIN et al., 2010).

\section{Saúde Mental Voltada ao Adolescente: Políticas Públicas}

Um dos maiores desafios para a Saúde Mental é a construção de uma política para crianças e adolescentes, que considere suas características específicas e suas necessidades, seguindo os princípios estabelecidos pelo Sistema Único de Saúde (SUS): universalidade, integralidade, equidade, descentralização e controle social. Um princípio fundamental é que toda e qualquer ação voltada para saúde mental de crianças e adolescentes precisa dialogar com outros campos, tais como: a ação social, a educação, a cultura, os esportes, os direitos humanos e a justiça (BRASIL, 2005).

Os problemas de saúde mental acometem de 10 a 20\% das crianças e adolescentes em todo o mundo. De 191 países pertencentes à Organização das Nações Unidas, em apenas 35 existem políticas voltadas para essa faixa etária e deles apenas sete possuem planos de ação claramente definidos para a saúde mental (ASSIS et al., 2009).

Historicamente, a Saúde Mental Infanto-Juvenil no Brasil, não teve nada estruturado ou sistematizado até o século XIX, quando surgiram as primeiras teses em Psicologia e em Psiquiatria. (RIBEIRO, 2006).

De modo geral, as políticas de saúde mental existentes estavam relacionadas aos problemas da população adulta. Para os adolescentes, os tipos de transtornos, principais fatores de risco e de proteção, estratégias de intervenção e organização do sistema de serviços têm especificidades que não podem ser contempladas pela simples extensão das estratégias de cuidado da população adulta à população infantil e juvenil (PATEL, 2007). Tais especificidades tendem a permanecer invisíveis na agenda mais geral das políticas de saúde mental, requerendo, assim, a proposição de uma agenda política específica. A inexistência de políticas de saúde mental para esses sujeitos em quase todas as partes do mundo torna o desenvolvimento de políticas nacionais de saúde mental não apenas necessário, como urgente (BELFER, 2008).

No Brasil, antes de existir uma política de assistência tem-se um tempo marcado pela segregação, exclusão, descaso, controle social e assistencialismo. (FERREIRA, 2004).

É fato recente o reconhecimento, pelas instâncias governamentais de nosso país, de que esta é uma questão de saúde pública e que deve integrar o conjunto de ações do SUS. Historicamente, as 
ações relacionadas à saúde mental da adolescência foram, no Brasil, delegadas aos setores educacionais e de assistência social, com quase ausência de proposições pela área da saúde mental (BRASIL, 2002a; BRASIL, 2005a).

É preciso romper com os limites administrativos dos serviços para uma maior integração das estratégias de apoio psicossocial. É necessário criar redes de suporte social tanto terapêuticas, como administrativas e políticas; "entendendo por administração e política um fluxo de interações entre atores sociais consolidando e desmontando instituições e, desta maneira, formando sociedade e Estado" (SILVA, 2009).

Com isso, fazem-se necessárias intervenções no campo político-administrativo que tragam maiores garantias às famílias. Uma vez que os progressos das ações de cuidado na comunidade devem estar apoiados em uma política de valorização do sujeito e de sua sustentabilidade social. As políticas de saúde para crianças e adolescentes, especialmente no campo da saúde mental, são resultado de um longo percurso de lutas, iniciado com o movimento de reforma da saúde e reforma psiquiátrica, que só vieram a se concretizar em 2001 com a definição da atenção especializada para crianças e adolescentes (REIS et al., 2010).

Em 2004, o Ministério da Saúde instalou o Fórum Nacional de Saúde Mental Infanto-Juvenil que tem por objetivo colocar à mostra as questões relativas ao campo da saúde mental de crianças e adolescentes e buscar resolvê-las. As atribuições do Fórum Nacional de Saúde Mental Infanto-Juvenil são:

- Funcionar como espaço de articulação entre os diversos setores que atuam na área da infância e da adolescência e de discussão permanente sobre as políticas para área de Saúde Mental Infanto-Juvenil, incentivando a criação de fóruns locais;

- Estabelecer diretrizes nacionais para a organização do conjunto de práticas que envolvam a atenção e o cuidado à Saúde Mental Infanto-juvenil;

- Possibilitar a integração, a articulação e o diálogo entre as diversas instituições que atuam no campo da atenção a crianças e adolescentes;

- Produzir e divulgar conhecimento e informações que subsidiem as instituições responsáveis pelas políticas públicas na área da infância e adolescência, nos diversos âmbitos de gestão;

- Elaborar recomendações e deliberações a serem transmitidas e implementadas na rede intersetorial de assistência. (BRASIL, 2005)

A discussão entre família e saúde faz-se necessária em virtude da repercussão das transformações sociais no campo da atenção à saúde mental e do processo de consolidação das políticas públicas destinadas a este setor. É um contexto de expectativas para as famílias e para os 
próprios gestores da saúde, de modo que se tornam necessários ajustes e reformulações de estratégias no campo das práticas, a todo tempo. Todo este cenário se apresenta como um espaço cultural, repleto de elementos significativos aos sujeitos, que agora se apresentam mais ativos frente a tais transformações, especialmente, no campo da saúde mental (AMARANTE, 1995).

Crianças e adolescentes passaram a ser vistos e valorizados socialmente com o Estatuto da Criança e do Adolescente (ECA), que juntamente com os movimentos de Reforma Psiquiátrica e Reforma Sanitária redefiniram a posição do Estado frente às crianças e adolescentes (REIS et al., 2010).

O ECA insere, no contexto da saúde do adolescente, a garantia de direitos. Dessa forma, consegue orientar a convivência familiar e comunitária de crianças e adolescentes. De acordo com ECA, o processo de proteção integral dessa população dá-se pela articulação e integração das políticas públicas voltadas para esses sujeitos, como forma de garantia de direitos. Isto implica que o atendimento das necessidades das crianças $\mathrm{e}$ adolescentes considera o direito do cidadão/criança/adolescente, cabendo ao Estado, à família e à sociedade a sua garantia (BRASIL, 2008).

No campo da saúde mental, o maior progresso prático foi a mudança do modelo de atenção, passando de uma prática focada na institucionalização para uma atenção comunitária. No centro deste modelo de atenção está o CAPSi (SILVA, 2012).

A integração da família nas estratégias de cuidado assume, com os CAPSi, uma dimensão nova em que eles celebram a relação existente entre o estatuto de sujeito de direito reconhecida ao adolescente e a criança pelo ECA e a situação de dependência desses sujeitos com o agrupamento familiar. A integração dos familiares nas estratégias de cuidado parece ter uma dimensão muito mais ampla do que a simples facilitação do contato de um adulto com a criança/adolescente, tal como poderia se pensar, em virtude da grande dependência desta população (BARBOSA et al., 2009; ROSA, 2005).

Foi após a Reforma Psiquiátrica, que os CAPSi passaram a se destacar no atendimento a crianças e adolescentes em sofrimento psíquico. Nestes, o atendimento não se limita somente ao momento de crise, mas adentra na continuidade da vida do usuário, inserido em sociedade e em seu sistema familiar. Assim, na assistência a crianças e adolescentes em sofrimento psíquico, é fundamental a inserção da família, especialmente nos modelos de atendimento do CAPS, no qual o paciente passa apenas parte do seu dia com os profissionais e retorna ao seio familiar (TÁVORA, 2011).

A presença de familiares em associações e na atuação junto aos CAPS promove uma ampliação do cenário terapêutico, permitindo múltiplas narrativas e possibilidades para pensar os diferentes níveis de complexidade envolvidos nesse processo (MELMAN, 2006). 
Trabalhar com famílias significa reconhecer a singularidade existente em cada sintoma no território familiar (ROMAGNOLI, 2004). O sintoma é um impedimento para a vivência da cotidianidade, pois dificulta os processos de reprodução de afetos (SILVA, 2012).

Portanto, constitui uma mudança profunda da dinâmica familiar, de tal modo que o núcleo familiar sofre uma desterritorialização. Isto leva a família a uma busca frustrada para restabelecer a situação anterior, ou seja, aquela conformação antes do adoecimento do seu integrante; ao invés de procurar elaborar uma nova formatação e dinâmica a partir do evento (ROMAGNOLI, 2004).

Com base no exposto, os profissionais de saúde devem prover recursos para as famílias se encontrarem e se reorganizarem em sua condição de existência; o que implica no enfrentamento das situações de crise e reelaboração das suas estratégias de sobrevivência em novas configurações e arranjos (SILVA, 2012).

É vital para a saúde mental da família, crescer a partir dessa situação de crise. É importante enfrentar o desafio de tornar mais leve o peso das grandes frustrações e transformar a dor em matériaprima de aprendizado e combustível para os processos de desenvolvimento (MELMAN, 2006).

É importante, então, que os serviços de saúde adaptem-se a essa sistemática, pois atuar com família deve ser também trabalhar em família, ou seja, com a consciência de que as partes, seus membros, fazem parte do todo familiar (AZEVEDO et al., 2009).

Diante disso, as novas práticas da atenção à saúde mental devem ser voltadas para o bem estar da criança e do adolescente em sofrimento psíquico, bem como para seu sistema familiar. Desta forma, busca-se pela reinserção do indivíduo na sociedade, possibilitando seu desempenho máximo nas atividades diárias, utilizando todo o seu potencial, vencendo as próprias limitações (TÁVOORA, 2011).

Algumas estratégias são significativas para o cuidado integral, tais como: o trabalho em equipe interdisciplinar e intersetorial, abordagem envolvendo a família, visita domiciliar, entre outras. Essas estratégias tem sido o foco dos serviços de saúde mental, especialmente, na dinâmica dos CAPSi (BRASIL, 2004).

As equipes que atuam nos CAPSi procuram agir de forma interdisciplinar, de modo a compartilhar os saberes entre os profissionais, no propósito de encontrar estratégias mais adequadas para cuidar dos adolescentes e sua família (SILVA, 2012).

É na expectativa de uma atenção voltada ao sistema familiar que supra as necessidades da criança, do adolescente e da família, que novas formas de cuidado estão sendo estudadas. Esses métodos surgem na busca pela reintegração daqueles que estão em sofrimento psíquico na sociedade, vivenciando o coletivo, alterando preconceitos existentes (TÁVORA, 2011).

Portanto, o cuidado ao adolescente tem a mediação direta da família, de modo que esta seja convidada a ser parceira na identificação, acolhimento e intervenção junto às necessidades e desejos 


\section{Trajeto Metodológico}

\section{Tipo de Pesquisa}

Trata-se de um estudo do tipo exploratório, de cunho descritivo, com abordagem qualitativa. Segundo Tomasi e Yamamoto (1998) a pesquisa descritiva busca conhecer diversas situações e relações que ocorrem na vida social, política, econômica e os aspectos do comportamento humano tanto de comunidades quanto do indivíduo isolado.

Leopardi (2002) afirma que a pesquisa exploratória "permite ao investigador aumentar a sua experiência em torno de um determinado problema. Consiste em explorar tipicamente a primeira aproximação de um tema e visa criar uma maior familiaridade a um fato ou fenômeno".

Para Minayo (1999) "as abordagens qualitativas se conformam melhor a investigações de grupos e segmentos delimitados e focalizados, de história social sob a ótica dos atores, de relações e para análises de discursos e de documentos".

A abordagem qualitativa contesta questões individuais. Onde tenta entender o problema da perspectiva do sujeito que o vivencia, incluindo sentimentos e desejos. A pesquisa qualitativa ajuda a identificar questões e entender porque elas são importantes. Também determina quais idéias geram uma forte reação emocional. Além disso, é especialmente útil em situações que envolvem o desenvolvimento e aperfeiçoamento de novas idéias (GIL, 1999).

Trata-se de uma abordagem qualitativa, onde é definida quando a evidência qualitativa substitui a simples informação estatística sobre épocas passadas a exemplos de estudos históricos (HAGUETTE, 1992).

Assim, consiste numa descrição de acontecimentos de alguma situação, que no futuro os resultados servirão para modificar as práticas (TRIVIÑOS, 1990).

\section{Cenário da Pesquisa}

Esse estudo foi realizado no serviço de saúde mental, mais especificamente no Centro de Atenção Psicossocial a Infância e Adolescência (CAPSi) da cidade de Iguatu. Essa instituição tem como componentes da equipe de saúde mental: 1 enfermeira, 1 psicóloga, 1 terapeuta ocupacional, 1 
fonoaudióloga, 2 pedagogas, 1 psiquiatra, 1 pediatra, 1 assistente social, 2 auxiliares de serviços gerais, 1 recepcionista, 1 auxiliar administrativo e 1 técnica de enfermagem.

O CAPSi passou a funcionar no ano de 2005 e é intitulado "Casa Azul". Seu público não se restringe apenas à própria cidade, fazendo assim, a cobertura das demais cidades vizinhas como: Jucás, Saboeiro, Cariús, Piquet Carneiro, Irapuan Pinheiro, Mombaça, Acopiara, Catarina e Quixelô (BRASIL, 2008).

O município de Iguatu localiza-se na Região Centro-Sul do estado do Ceará, distante $384 \mathrm{~km}$ de Fortaleza, capital do Estado. A cidade de Iguatu apresenta uma área de 4.811,40 km², com população de 98.138 habitantes segundo o IBGE (2012), apresentando clima semi-árido e temperatura média de $26^{\circ} \mathrm{C}$. O município é destacado pelo comércio, além, de atuar como fornecedor de serviços médicos e educacionais para mais de nove municípios cearenses.

Os aspectos sociais e culturais estão evidenciados na religiosidade local pela devoção popular à padroeira Nossa Senhora Santana e no campo artístico por ter sido terra natal dos compositores Eleazar de Carvalho e Humberto Cavalcanti Teixeira. O rio Jaguaribe tem influencia direta com o desenvolvimento agrícola do município. Atualmente, as diversas lagoas e o açude Trussu são fundamentais para a agricultura e piscicultura efetivada na região (SAMPAIO, 2008).

\section{Sujeitos do Estudo}

O público alvo foram os familiares de adolescentes usuários dos serviços do CAPSi de Iguatu.

Foi escolhido o CAPSi por receber e realizar o tratamento de adolescentes com transtornos mentais. Realizou-se uma entrevista semiestruturada composta por questões norteadoras com os familiares dos usuários em questão, afim de que se possa ter um maior conhecimento sobre a assistência prestada por esses profissionais de saúde e o vínculo participativo entre profissionais e familiares.

Os critérios de inclusão e exclusão para a seleção dos sujeitos da pesquisa foram: 1. Aceitar espontaneamente participar da pesquisa e assinar o Termo de Consentimento Livre e Esclarecido (APÊNDICE A), respeitando os itens constantes da Resolução 196/96 sobre as Diretrizes e Normas Regulamentadoras de Pesquisa em Seres Humanos; 2. Ser familiar ou cuidador do adolescente cliente da CAPSi de Iguatu; 3. Ser maior de idade.

Para Exclusão foram utilizados: 1. Não ser familiar ou cuidador de adolescente usuário do CAPSi; 2. Não residir na área de cobertura do CAPSI de Iguatu; 


\section{Instrumento de Coleta de dados}

No intuito de alcançar os objetivos da pesquisa, o instrumento de coleta de dados foi através da entrevista semiestruturada (APÊNDICE B), com os familiares dos adolescentes com transtornos psíquicos, que abordou inicialmente dados socioeconômicos e culturais e, em seguida, questões norteadoras sobre a temática.

A entrevista semiestruturada foi escolhida por ser um instrumento flexível, no qual existe um roteiro preliminar contendo uma combinação de perguntas abertas e fechadas, onde o informante tem a possibilidade de discorrer sobre o tema proposto. Desse modo, o entrevistador segue um conjunto de questões previamente definidas, no entanto, ele o faz em um contexto muito mais semelhante ao de uma conversa informal, favorecendo uma abertura e proximidade maior com o entrevistado, obtendo, conseqüentemente, respostas espontâneas (BONI; QUARESMA, 2005).

Gil afirma que:

A entrevista tem a vantagem essencial de que são os atores sociais mesmo que proporciona os dados relativos às suas condutas, desejos e expectativas [...] Ninguém melhor do que a própria pessoa envolvida, para falar sobre aquilo que pensa e sente do que tem experimentado (Gil, 2002, p. 176).

A coleta foi realizada durante o mês de janeiro de 2013 e os dados foram obtidos por um único observador, que repassou aos participantes a livre escolha de desistência à participação da pesquisa. Após o esclarecimento dos objetivos do estudo, os participantes assinaram o termo de consentimento livre e esclarecido para comprovar a autorização na participação do estudo. Ressalta-se que o anonimato dos pesquisados foi mantido, e para tanto, foram utilizados pseudônimos com referência a nome de flores. Para uma interpretação mais fidedigna dos dados foi utilizado, durante a coleta dos dados, um gravador de voz.

\section{Análise de Conteúdo}

Para Minayo (2007 p.26-27):

A análise de dados diz respeito ao conjunto de procedimentos para valorizar, compreender, interpretar os dados empíricos, articulá-los com a teoria que fundamentou o projeto ou com outras leituras teóricas e interpretativas cuja necessidade foi dada pelo trabalho de campo. (MINAYO, 2007, p.26-27). 
http://idonline.emnuvens.com.br/id ISSN on-line: 1981-1179

As informações coletadas foram analisadas seguindo-se classificações categóricas de acordo com o exposto pelos entrevistados. A análise das falas seguiu os passos metodológicos propostos por Minayo (2007): ordenação dos dados, classificação dos dados e análise final.

\section{Aspectos Éticos e Legais da Pesquisa}

Os aspectos éticos estiveram presentes em todas as fases da pesquisa como diz a resolução 196/96 do Conselho Nacional da Saúde/Ministério da Saúde, que aborda as pesquisas envolvendo seres humanos, sob a visão do indivíduo e da coletividade (BRASIL, 2000).

O local utilizado para coleta de dados recebeu um ofício contendo as informações sobre a pesquisa, bem como o Pedido de Autorização (Apêndice D) para a realização da mesma.

Foi utilizado um Termo de Consentimento (APÊNDICE A) que foi assinado por todos os participantes da pesquisa. Esse termo de consentimento obedeceu aos quatro princípios básicos da bioética que são: autonomia, não maleficência, beneficência e justiça, assegurando assim os direitos e deveres dos sujeitos da pesquisa. Aos sujeitos da pesquisa, foi garantido a participação voluntária, o direito ao anonimato, o não pronunciamento quando acharem conveniente bem como a possibilidade de se retirarem da pesquisa a qualquer momento.

Em se tratando dos aspectos éticos em pesquisa envolvendo seres humanos, consta na Resolução 196/96 que: "toda pesquisa envolvendo seres humanos envolve riscos. O dano eventual poderá ser imediato ou tardio, comprometendo o indivíduo ou a coletividade" (BRASIL, 2000). Sendo assim, a pesquisadora fica responsável, caso necessário, por suspender o projeto de pesquisa imediatamente se perceber algum risco ou dano à saúde dos sujeitos participantes.

A pesquisa foi submetida à análise do Comitê de Ética em Pesquisa (CEP) da Universidade Regional do Cariri (URCA), onde se encontra em processo de avaliação.

\section{Análise E Discussão Dos Dados}

Os resultados do presente estudo e sua respectiva discussão serão relatados a seguir em duas etapas apresentando, respectivamente, as características pessoais e socioeconômicas dos participantes e o contexto da pesquisa nas categorias temáticas. 


\section{Caracterização dos Sujeitos do Estudo}

Nessa categoria serão apresentados os dados coletados referentes à idade, estado civil, gênero, familiaridade, escolaridade e renda familiar dos entrevistados. Os dados serão dispostos em tabelas contendo os percentis de cada valor absoluto obtido por meio da pesquisa, e posteriormente, relacionados com literaturas semelhantes ou que abordem o assunto exposto.

\section{Características Pessoais}

Com relação à faixa etária dos entrevistados, o estudo mostra que quatro dos participantes (40\%) têm acima de 50 anos de idade, três (30\%) tem de 31 a 40 anos, dois (20\%) tem de 21 a 30 anos e apenas um dos participantes (10\%) tem entre 41 e 50 anos (tabela 1).

Tabela 1- Perfil dos participantes quanto à idade

\begin{tabular}{ccc}
\hline IDADE & VALOR ABSOLUTO & PERCENTUAL (\%) \\
\hline $21-30$ anos & 2 & $20 \%$ \\
$31-40$ anos & 3 & $30 \%$ \\
$41-50$ anos & 1 & $10 \%$ \\
Acima de 50 anos & 4 & $40 \%$ \\
\hline Total & $\mathbf{1 0}$ & $\mathbf{1 0 0 \%}$ \\
\hline
\end{tabular}

Fonte: Pesquisa direta, Iguatu- Ce, 2013.

Quanto ao gênero, foram entrevistados dez familiares do sexo feminino (tabela 2). $O$ fato de todos os cuidadores serem deste sexo, corrobora com dados do estudo de Queiroz (2000), que diz que as mulheres são, em nossa sociedade, cuidadoras por excelência e que existem influencias culturais para que isso aconteça, pois em épocas passadas, a mulher ficava em casa cuidando dos filhos e das atividades domésticas, enquanto o homem saía para prover o sustento do lar.

Salci (2008) diz que a respeito de todas as transformações ocorridas no papel da mulher na sociedade através das gerações, suscita o surgimento de novas práticas relacionadas ao viver em família, pois a mulher continua sendo a principal responsável pela criação dos filhos. Os cuidados desenvolvidos pelas mulheres acontecem tanto no âmbito físico como emocional e psicossocial. A ação cuidadora é permeada ainda de dificuldades nas atividades básicas de manutenção da vida, uma vez que são realizadas concomitantemente ao cuidado da casa, resultando numa jornada contínua e solitária.

Id en line Revista de Psicologia. Ano 8, No. 22, Fevereiro/2014 - ISSN 1981-1179. Edição eletrônica em http://idonline.emnuvens.com.br/id 
Portanto, faz-se necessário ressaltar que, de certa forma, e em grande maioria dos casos, o sexo feminino garante o funcionamento e a própria existência da família.

Tabela 2 - Perfil dos participantes quanto ao gênero

\begin{tabular}{ccc}
\hline GÊNERO & VALOR ABSOLUTO & PERCENTUAL \\
Masculino & 0 & 0 \\
Feminino & 10 & $100 \%$ \\
\hline TOTAL & $\mathbf{1 0}$ & $\mathbf{1 0 0 \%}$ \\
\hline
\end{tabular}

Fonte: Pesquisa direta, Iguatu- Ce, 2013.

No que diz respeito ao estado civil das entrevistadas, $60 \%$ são casadas (tabela 3), o que vem a discordar com os dados do Censo 2010, onde o primeiro lugar foi ocupado pelo estado civil solteiro, que compôs 23. 717 mil pessoas das 43.281 mil de 10 anos ou mais, ocorrendo à inversão na amostragem (IBGE, 2010).

Esse fato nos mostra que a maioria da população em estudo ainda é constituída por famílias que convivem com a situação do casamento ou de uma união estável, mantendo, assim, preservados as bases e preceitos familiares, organizadas com pai, mãe e filhos, em sua maioria.

Tabela 3: Perfil dos participantes quanto ao estado civil

\begin{tabular}{ccc}
\hline ESTADO CIVIL & VALOR ABSOLUTO & PERCENTUAL \\
\hline Casada & 6 & $60 \%$ \\
Solteira & 3 & $30 \%$ \\
Viúva & 0 & 0 \\
Divorciada & 1 & $10 \%$ \\
Total & $\mathbf{1 0}$ & $\mathbf{1 0 0 \%}$ \\
\hline
\end{tabular}

Fonte: Pesquisa direta, Iguatu- Ce, 2013.

Com relação à familiaridade, foi visto que a maioria dos cuidadores são as próprias mães sanguíneas (50\% dos casos estudados) e em segundo lugar as mães adotivas (30\% dos casos) (tabela 4). Sendo assim, os dados corroboram com a literatura de Pegoraro (2006) que indica as mães como as principais cuidadoras e que elas sentem mais sobrecarga do que os demais familiares.

A criança, logo ao nascer, necessita de contato afetivo contínuo, advindo de uma figura constante - comumente a sua mãe - com a qual estabelecerá relações de apego que favorecem seu desenvolvimento biopsicoafetivo. Já para mulher que dá à luz, o momento inicial após o parto é 
considerado precursor do apego, a primeira oportunidade da mãe de ser sensibilizada pelo seu bebê e principiar o exercício social da maternidade (GASPERI, 2008).

Visto isso, percebemos que o vínculo entre mãe e filho acaba por, na maioria das vezes, eleger a mãe como principal cuidadora. Para ela, permanecer ao lado do filho, representa a possibilidade de acompanhar a evolução da doença e poder contribuir com sua recuperação. As matriarcas acreditam que seus filhos choram menos, ficam mais calmos, se recuperam mais rápido e se sentem mais protegidos, quando estão envoltos pelo carinho e cuidado materno. Esta percepção da mãe acaba sendo de suma importância para auxiliar o adolescente a enfrentar sua patologia (COLLET, 2003).

Tabela 4: Perfil dos participantes quanto à familiaridade

\begin{tabular}{ccc}
\hline FAMILIARIDADE & VALOR ABSOLUTO & PERCENTUAL \\
\hline Mãe & 5 & $50 \%$ \\
Mãe adotiva & 3 & $30 \%$ \\
Pai & 0 & 0 \\
Avó & 1 & $10 \%$ \\
Outros & 1 & $10 \%$ \\
\hline Total & $\mathbf{1 0}$ & $\mathbf{1 0 0 \%}$ \\
\hline
\end{tabular}

Fonte: Pesquisa direta, Iguatu- Ce, 2013.

\section{Características sócio-econômicas}

Quanto ao aprimoramento escolar da população em estudo, percebeu-se que a maioria, formada por $40 \%$ dos casos, possui o ensino fundamental completo (tabela 5). Essa paridade vem a expor o baixo grau de escolaridade das cuidadoras estudadas, o que cria algumas limitações quanto ao cuidado prestado por elas aos adolescentes, pois a falta de informação e estudos pode desacelerar o processo de início do tratamento e até mesmo a evolução deste.

Adquirir conhecimentos através do estudo é sinônimo de receber informações, ou seja, pessoas com maior nível de escolaridade são mais sensibilizadas e atentas a qualquer anormalidade funcional do organismo, seja ela física ou mental, conseguindo assim, de imediato, identificar qual o serviço de saúde procurar.

Dessa forma, os dados apresentados pela abordagem concordam com o Ministério da Saúde que diz que o grau de escolaridade é um aspecto essencial a ser considerado na abordagem da população quanto às práticas de promoção, prevenção e recuperação da saúde (BRASIL, 2004). 
Tabela 5: Perfil dos participantes quanto à escolaridade

\begin{tabular}{ccc}
\hline ESCOLARIDADE & VALOR ABSOLUTO & PERCENTUAL \\
\hline Sem Instruções & 1 & $10 \%$ \\
Fundamental Incompleto & 2 & $20 \%$ \\
Fundamental Completo & 4 & $40 \%$ \\
Médio Incompleto & 0 & 0 \\
Médio Completo & 3 & $30 \%$ \\
Superior & 0 & 0 \\
\hline Total & $\mathbf{1 0}$ & $\mathbf{1 0 0 \%}$ \\
\hline
\end{tabular}

Fonte: Pesquisa direta, Iguatu- Ce, 2013.

Em se tratando de renda familiar, verificou-se que três das entrevistadas não possuíam renda familiar fixa, sendo esta variação, menor que 1 salário mínimo. Cinco das participantes (50\%) possuíam como renda 1 salário mínimo, uma (10\%) possuía de 2 a 3 salários e apenas uma (10\%) possuía acima 4 salários, conforme a tabela 6 .

O baixo poder aquisitivo das famílias torna o enfrentamento da doença mental ainda mais difícil, pois este processo, de certa forma, demanda despesas financeiras gerando sentimentos de preocupação e angústia para os entes.

Sendo assim, nota-se a similaridade entre os índices apresentados na tabela 6 com a literatura de Campos (2005), que evidencia o discurso sobre as perdas financeiras por parte do cuidador que em, alguns casos, precisou alterar sua situação de trabalho, em função da demanda da atividade de cuidar do parente, além dos gastos com consultas, medicações e deslocamento.

Tabela 6: Perfil dos participantes quanto à renda familiar

\begin{tabular}{ccc}
\hline RENDA FAMILIAR & VALOR ABSOLUTO & PERCENTUAL \\
\hline$<$ 1 Salário & 3 & $30 \%$ \\
1 Salário & 5 & $50 \%$ \\
2 a 3 salários & 1 & $10 \%$ \\
4 ou mais & 1 & $10 \%$ \\
\hline Total & $\mathbf{1 0}$ & $\mathbf{1 0 0 \%}$ \\
\hline
\end{tabular}

Fonte: Pesquisa direta, Iguatu- Ce, 2013.

\section{Questões Norteadoras}

Os dados obtidos através das entrevistas foram agrupados em categorias para explanação minuciosa dos resultados, comparando-se sempre com a literatura pertinente, para alcançar os objetivos propostos por este estudo. 


\section{Reação do familiar ou cuidador ao ter conhecimento da necessidade do adolescente realizar tratamento no CAPSi.}

Para contemplar essa categoria, investigou-se qual foi a reação das participantes, ao ter conhecimento da necessidade do adolescente sob seus cuidados, realizar tratamento no CAPSi. Descobriu-se que a maior parte das entrevistadas definiu a situação como triste. Apenas três das familiares citaram ter reagido bem à notícia. Assim, fica nítido que a maioria das participantes reagiu de forma negativa, expressando inconformação através de episódios de choro, o que pode ser evidenciado nas seguintes falas:

Num é fácil não. Porque a gente quer que o filho da gente venha com saúde, e tudo. E até hoje eu sofro muito com isso, porque ele dá bastante trabalho, e tudo, só que a gente tem que agradecer o que Deus dá a gente. Se Deus me deu ele, é porque Ele sabe que eu posso seguir em frente. (Margarida)

É ruim, mas é coisa da vida. (Violeta)

Eu não tava percebendo que ele precisava desse tipo de tratamento, mas como ele não é normal pra falar como a gente, aí foi na escola descobriram. Quando eu descobri num me senti bem não, me senti triste. Até chorei. Fiquei preocupada. (Orquídea)

Eu fiquei: tomara que dê tudo certo, que ele melhore. A pessoa fica triste. A pessoa saber que o filho tem problema assim. (Girassol)

Bom, foi um choque assim, pra mim. Ninguém nunca espera ter um filho assim, com problema. Mas é aceitar e torcer pra que ele se recupere e fique bom se possível. A gente espera como mãe. Tem fé que chegue lá. (Rosa)

Aí eu fiquei só chorando, ele ter que vir pra cá. (Cravo)

É constrangedor, entendeu? A gente nunca tá preparada no total, mas tem que tá preparada pra alguma coisa. Fiquei apreensiva e preocupada. Chorei muito. (Papoula)

De acordo com os discursos apresentados, os dados corroboram com a ideia de que quando duas pessoas planejam ter filhos, nunca se imagina um bebê com alguma deficiência, sendo, esta situação, algo não desejado. Ninguém aprende a ser mãe de uma criança deficiente antes de tê-la. Conforme a autora Cerveny (2004), a entrada de uma criança com necessidades especiais muda o clima emocional da família de um modo diferente da que recebe uma criança sem as mesmas dificuldades (AMIRALIAN, 1986).

Hirdes (2005) indica uma estreita relação entre o conhecimento da necessidade de um tratamento mental por um adolescente, e o sofrimento de seus familiares. Ela afirma que é forte a 
devastação causada pelo diagnóstico quando a família toma conhecimento da doença mental. Esse tipo de diagnóstico tem a propriedade de gerar um sentimento inexplicável, um vazio, uma baixa condição da qualidade de vida. Sentimentos derivados passam a fazer parte desse cotidiano, como o medo, a tristeza, a vergonha e a piedade, um aglomerado de ações ou efeitos do sentir.

A insegurança de como será o amanhã desses adolescentes, é algo que os familiares demonstraram constantemente. A dúvida que rodeia a família quanto à recuperação ou melhora de seu familiar, mesmo seguida por uma palavra de esperança, corrói a qualidade de vida de todos que tem contato com a problemática mental.

Para aprender a conviver com essa realidade, a família passa por várias fases, e cada família apresenta reações diferentes nesse processo de compreensão e aceitação desse filho. A primeira fase seria o choque, querendo buscar culpados e querendo saber o porquê disso ter ocorrido; a segunda fase é a negação, na qual vão à busca de um diagnostico errado ou de cura, até as esperanças se esgotarem; na terceira fase, a cólera, os familiares afastam-se do mundo, para vivenciar o luto; na quarta fase há a convivência com a realidade. Neste período o desequilíbrio entre aceitação e rejeição é grande, algumas vezes tendo facilidade e outras dificuldades sobre o filho deficiente. Na quinta fase temos as expectativas frente ao futuro, onde há uma variação quanto ao medo, a insegurança, entre outros sentimentos. (CERVENY, 2004).

A sensibilidade existente entre os integrantes de um seio familiar é afetada, principalmente, quando se trata do sofrimento de outro membro. O vínculo de proteção é instigado a crescer e todos sentem, proporcionalmente, a dor causada pela ausência de saúde do indivíduo. Esta ausência pode fazer com que, sem equilíbrio e apoio suficiente, os demais familiares venham a desenvolver, até mesmo sem perceber e ter a devida consciência sobre, algum desequilíbrio emocional ou físico.

Os familiares sofrem, porque têm consciência da doença. Evidencia- se nos entes um sentimento de tristeza misturado com o carinho sentido pelo portador de transtorno mental. A família é atingida profundamente pelo sofrimento que perpassa o seu viver em todos os níveis, tornando-se o companheiro de todas as horas, ao longo da trajetória da doença do familiar. Esse sofrimento manifesta-se de diferentes formas e intensidades, deixando marcas profundas na vida dos envolvidos (HIRDES, 2005).

\section{O cuidado da família ao adolescente com transtorno mental}

Nesta categoria foi questionado aos familiares sobre o cuidado com os adolescentes clientes do CAPSi. Das dez participantes da pesquisa, todas relataram uma intensa dedicação ao desenvolver 
os cuidados diários dos jovens portadores de transtorno mental e 06 relataram ter a ajuda de outros familiares nesses cuidados, destacando o quão é importante à participação e ajuda da família.

Eu cuido dela. Trago nos dias certos, direitinho. Converso, dou carinho. Todos ajudam. (Jasmim)

Assim, eu tento brincar com ele, ele quer muita atenção, quer brincar. Tanto eu como o pai dele ainda brincamos muito com ele, a gente é muito atencioso com ele. Porque ele precisa muito de atenção mesmo. A minha família aceita, até me ajuda. Minha família é meu tudo. Se num fosse a minha família num sei nem o que seria de mim. (Margarida)

Eu faço tudo que eu posso e o que num posso. Dou uma atenção maior, por cima de tudo. Tudo que eu for capaz de fazer. Todo mundo cuida dele. Todo mundo ajuda. Todos lá de casa tem muita atenção com ele. Fazem sempre o que podem fazer. (Violeta)

Minha ajuda tem sido necessária, até porque ela só tem o pai, e é filha adotada dele. Tem duas tias dela que ajudam em casa e até mesmo na questão de educar. (Lírio)

Minha participação é tudo. Na idade que ele tá ele diz que eu sou tudo na vida dele. A minha mãe sempre me ajudou com ele. Ela mora comigo e ele hoje. (Tulipa)

Tô acompanhando o tratamento dele. É até bom saber que ele vai melhorar, é muito bom. É só mesmo eu e o pai dele e a irmã dele ajuda também. Ela dá muito conselho assim, sempre tratando dele. (Girassol)

Assim, as falas a cima dispostas, confirmam que o cuidado leva a uma necessidade de compreensão dos sujeitos em suas essências, indo ao encontro de Silva (2012), o qual destaca que no âmbito familiar, as emoções distinguem quais os membros que estão mais próximos e dispostos a ajudar durante o tratamento.

Segundo Hirdes (2005), a experiência de ter um membro da família com doença mental, mobiliza esta família como um todo no seu dia-a-dia, independente da forma como ela vem se constituindo, em razão de ser muito difícil necessitar desse familiar e ele não poder colaborar no cotidiano familiar. A presença de uma pessoa com transtorno mental produz um impacto nos outros membros da família, tendo em vista que, os familiares ficam sobrecarregados por demandas que envolvem a função de acompanhar seus membros adoecidos e cuidar deles. Essa sobrecarga familiar é sentida não somente nos aspectos emocional e físico, mas também nos encargos econômicos, o que implica uma situação de dependência da família. Esse pensamento da autora citada é identificado nas seguintes falas:

Id en line Revista de Psicologia. Ano 8, No. 22, Fevereiro/2014 - ISSN 1981-1179. Edição eletrônica em http://idonline.emnuvens.com.br/id 
A rotina da casa mudou bastante depois do nascimento dele. Porque assim, eu e meu marido, a gente não tem mais a privacidade de tá só, de sair, por que a única pessoa que ele fica é com minha mãe. Ele chora, chora muito. Acho que ele sente como se a gente fosse embora, fosse abandonar ele entendeu? É isso, porque todo casal tem que ter aquela privacidade, e tudo. (Margarida)

Ele tá recebendo o benefício, melhorou mais um pouquinho, mas num dá nem pra começar o que ele tá recebendo. Sou eu sozinha pra cuidar dele. Enquanto ele for vivo, ele vai ter que tomar esses remédios .(Cravo)

Ao realizar as entrevistas, foi perceptível o aspecto cansado e fadigado expresso pelas faces dos familiares que ali estavam. Os relatos, sempre semelhantes, faziam uma constante referência ao abalo emocional e físico que aqueles cuidadores enfrentavam diariamente. Contudo, o amor por seus entes e a esperança de recuperação, os ajudava a enfrentar e prosseguir diante de tão pesada responsabilidade.

Percebe-se que a disposição da família em cuidar de seu doente, exige um envolvimento que acolha a dor e o sofrimento do outro, oferecendo-lhe apoio e solidariedade (OLIVEIRA, 2001).

\section{Entendimento dos cuidadores a respeito da importância e função do CAPSi}

Os familiares são unanimes em verbalizar que acham de grande valia o trabalho desenvolvido no Centro de Atenção Psicossocial para Crianças e Adolescentes. Contudo, durante as entrevistas, identificou-se, por parte dos participantes, dificuldades em descrever de forma objetiva a importância do CAPSi e uma total alienação sobre as funções da instituição. Esse fato pode ser notado a partir das falas:

Bom, pra gente, o tratamento tem sido necessário, se ela tá de uma certa forma melhorando, foi graças ao CAPSi. Se não fosse a ajuda, se não fosse a gente ter procurado e eles terem nos acolhido, com certeza ela já teria ido embora, não estaria mais com a gente, nós não saberíamos mais lidar com ela. Agora a função real do CAPSi eu não sei dizer. Acho que esse esclarecimento poderia ser dado pra gente no início do tratamento. (Lírio)

Pra mim foi muito importante, porque quando ela chegou nem falava, nem andava direito, e daí, foi aqui que ela aprendeu muita coisa. (Jasmim)

Eu acho muito importante, porque pra gente que é mãe, sozinha a gente não daria conta. E eles tem um carinho enorme, eles tem uma atenção com os filhos, que não é filhos deles, e tudo. E eu tenho certeza que eles trabalha, não é só pelo dinheiro, tenho certeza que é pelo amor do que faz. Eu acho muito importante. Foi a melhor coisa que aconteceu. (Margarida)

Eu acho um trabalho importante. Um trabalho que é pra ajudar as crianças que precisa. Então eles dão o máximo de si pra eles. Eu acho muito bom. Penso assim, que se não existisse a casa azul o que seria de nossas crianças que precisa de ajuda 
e num pode pagar? Só tenho que gradecer a Deus, porque se a gente não tivesse tudo seria mais difícil. (Rosa)

Acho muito importante. Porque assim, aqui eles dão muita atenção, ele nunca tinha passado numa psiquiatra, aí graças a Deus ele tá sendo medicado, tá melhorando. Acho que se ele tivesse um acompanhamento de uma psicóloga ele já tinha mudado muito. Porque é só eu e ele, aí você sabe que a doença quando dá na pessoa, ela não quer contato com a outra que lida com ela. Outro de fora já é mais fácil dele atender, com certeza. (Papoula)

Navarini e Hirdes (2008) e Barroso et al. (2009) afirmam que ainda são insuficientes as informações fornecidas pela equipe de saúde aos familiares acerca das diversas situações do dia a dia, sendo, portanto, lacuna na atenção à saúde mental.

Muitos familiares expressam a necessidade de esclarecimentos acerca da doença, do cuidar, da evolução do tratamento ou de um acompanhamento individual para a criança ou o adolescente, assim como também esclarecimentos de como funciona e qual o objetivo do CAPSi (COLVERO et al., 2004; MORENO, 2009).

Os familiares reconhecem o avanço do adolescente após o inicio do tratamento do CAPSi, contudo, não conseguem expor isso de maneiro clara, sendo perceptível a falta de orientação sobre o serviço. Dessa forma, o estudo mostra que a informação aos familiares é necessária para que estes tenham conhecimento e entendimento suficientes durante o decorrer do tratamento de seu familiar, desenvolvendo assim, uma rica e satisfatória contribuição.

\section{Relação existente entre a equipe de saúde do CAPSi e familiares}

A investigação sobre o acolhimento do CAPSi e a interação entre a equipe de saúde mental e os familiares, evidenciou grande satisfação por parte dos entrevistados. Essa realidade pode ser apreciada a partir das falas:

Aqui eles dão a liberdade pra gente se expressar e as crianças desenvolverem cada vez mais. Com certeza. Abrem espaço sim. As crianças interagem umas com as outras, tem reuniões com os pais todos os meses. (Jasmim)

Eles pede pra falar tudo que tá acontecendo, eles dão aquela liberdade pra gente, aí é muito importante pra mim. Aqui eu me sinto bem recebida, como se eu tivesse em casa. Tem até festinhas, que é no tempo do carnaval, festa junina. Tem reuniões dos pais. Explicam como a gente pode ajudar no desenvolvimento deles. É muito importante. (Margarida)

Pergunto, eles explica. Se gente precisa de alguma coisa elas fazem. Eu gosto. Mas o meu menino não quer contato com os outros. Ele não tem contato com outras 
pessoas. Ele não quer vir, aí eu tenho que vir só. Se ele vier aqui e tiver uma pessoa que ele não gostou, ele já num vem mais. Eles dão espaço, mas eu moro no sítio e tenho que pagar passagem. Quando tem reunião ou festinha é difícil eu vir, mas sempre sou convidada. Acho que temo muita abertura aqui. (Violeta)

Eu acho muito bom. Ele desenvolveu a escrita e a leitura dele foi aqui. Já passou por todos os profissionais. Eles dão toda a atenção que podem. Num tenho o que falar daqui da casa azul não. Fazem festinhas e tudo. (Tulipa)

A gente se sente a vontade. Eles num tem assim, cara feia, aborrecimento. Eu nunca fui mal tratada. A gente procura conversar, eles atende. Deixa bem a vontade. Fazem reuniões, é acolhimento completo. (Rosa)

Me sinto muito a vontade com qualquer um. Os profissionais são ótimos, são excelentes. Abrem bastante espaço pra gente, dá até pra conhecer as otras mãe. (Papoula)

A importância da família como parceira no novo modelo de atenção vai sendo reconhecida pelos serviços de saúde mental à medida que se percebe que ela é o principal agente na ressocialização do paciente (PEREIRA, 2003). Esse reconhecimento é tornado oficial a partir da Lei 10.216, que dentre outras atribuições, fala da responsabilidade da família no tratamento.

O desenvolvimento da política de saúde mental, a assistência e a promoção de ações de saúde aos portadores de transtornos mentais, com a devida participação da sociedade e da família, são de responsabilidade do Estado. Essa assistência deverá ser prestada em instituições ou unidades que ofereçam assistência em saúde aos portadores de transtornos mentais (BRASIL, 2004).

Esperidião (2001) afirma que é fundamental o apoio à família e sua orientação e que quando isso ocorre, a mesma se sente mais aberta a falar de seus problemas e acaba por se mostrar uma estrutura importante tanto para a desinstitucionalização quanto para a reinserção social do sujeito.

Assim, com essa nova postura diante ao tratamento, onde a família é vista como peça-chave para o seu progresso, é necessário que se reveja a relação entre os serviços, usuários e seus familiares. Como fala Pereira (2003) ampliam-se as possibilidades de uma assistência mais digna e global, a partir da desconstrução de conceitos, atuando em direção as transformações que se fazem necessárias na relação entre profissionais de saúde mental, os pacientes e suas famílias.

Para Amarante (1994), um trabalho voltado para os familiares deve levar em conta as dinâmicas das diferentes pessoas, diferentes famílias e diferentes culturas. Transformando, desta forma, as instituições de saúde em um espaço social onde se permita a reprodução do sujeito, produção de subjetividades, o exercício de auto-ajuda, convivência, sociabilidade, solidariedade e integração.

O espaço de tratamento deve permitir e não repreender. Deve ser a ponte entre a família e o paciente. Mediador entre as relações e local onde o familiar se sinta acolhido e confortável, onde encontre sustentação para superar as suas dificuldades e poder melhorar a qualidade de vida não só do paciente, mas de todos os membros (MELMAN, 2006). 
A partir da análise das entrevistas foi possível constatar que as práticas encontradas no serviço estudado são condizentes com as diretrizes políticas para a atenção a essa clientela. Os serviços se mostram empenhados em melhorar cada vez mais essa assistência e há um diálogo constante entre profissionais e familiares visando aprimorar esse atendimento, o que acaba por gerar o reconhecimento por parte do familiar sobre a importância da aproximação serviço/família.

\section{Considerações Finais}

No Brasil, as principais mudanças na legislação em saúde mental ocorreram no final dos anos 1970 e início dos anos 1980, juntamente com o movimento da Reforma Psiquiátrica, da Reforma Sanitária e do Movimento dos Trabalhadores. A partir desse momento, a saúde mental brasileira iniciou um processo de avanços, junto à desinstitucionalização da loucura.

O cuidar a um indivíduo com transtornos psíquicos, exige da família máxima atenção e dedicação constantes, principalmente, se esse indivíduo, encontrar-se em um período tão complexo como a adolescência. Essa fase produz grandes tensões e questionamentos tanto para os adolescentes como para sua família. A insegurança quanto ao futuro desses jovens é um dos maiores medos e anseios dos familiares.

A família tem como principal papel, identificar, inserir e proteger o indivíduo frente à sociedade. Sabe-se hoje, que o seio familiar é o maior responsável pela formação do sujeito e que a participação dos entes, junto às equipes de saúde mental, é de fundamental importância para um resultado satisfatório, no que diz respeito ao tratamento de adolescentes com transtornos psiquiátricos.

$\mathrm{O}$ estudo em questão buscou conhecer a importância do vinculo familiar junto ao tratamento e reabilitação de adolescentes clientes do CAPSi do município de Iguatu. Todas as entrevistas foram realizadas com pessoas do sexo feminino, contatando-se a existência de alguns aspectos coincidentes entre o perfil das familiares em estudo e o encontrado na literatura cientifica.

Nesta pesquisa, constatou-se que a grande maioria das famílias não reagiu bem ao diagnóstico de que seus membros necessitariam de tratamento no CAPSi, demonstrando com isso, muitos episódios de tristeza e inconformação.

Notou-se que as principais provedoras do cuidado aos adolescentes portadores de problemas mentais são as mães, revelando-se nestas mulheres, grandes dificuldades em assumir uma responsabilidade tão intensa e desgastante.

Quando indagadas sobre o conhecimento acerca da função do CAPSi, nenhuma das mulheres conseguiu chegar a uma resposta precisa. Este fato reflete a falha da assistência prestada pelos 
profissionais de saúde mental da instituição, quanto à informação de como funciona e qual o objetivo do Centro de Atenção Psicossocial para Crianças e Adolescentes.

Já no que diz respeito à interação dos profissionais de saúde para com os familiares, percebeuse uma imensa satisfação e agradecimento por parte das mães, que relataram, em diversos momentos, vários elogios à equipe multiprofissional.

Sendo assim torna-se necessário à criação de estratégias que forneçam informações constantes sobre a importância da participação da família junto ao tratamento psiquiátrico dos adolescentes e soluções que mudem a realidade sobre a desinformação dos familiares sobre a instituição do CAPSi.

Espera-se que este estudo tenha fornecido dados relevantes sobre o assunto e que possa auxiliar as autoridades, profissionais e demais acadêmicos da área, na avaliação quanto às ações atualmente desenvolvidas pelo Centro de Atenção Psicossocial para Crianças e Adolescentes juntc familiares.

\section{Referências}

ABERASTURY, A.; KNOBEL, M. Adolescência normal: um enfoque psicanalítico. Porto Alegre: Artmed, 1981.

AMARANTE, P. Loucos pela Vida: a trajetória da Reforma Psiquiátrica no Brasil. Rio de Janeiro (RJ): Fiocruz, 1995.

AMARANTE, P. e GIOVANELLA, L. O enfoque estratégico do planejamento em saúde mental. In: AMARANTE P, organizador. Psiquiatria Social e Reforma Psiquiátrica. Rio de Janeiro: FIOCRUZ; 1994.

AMIRALIAN, M. L. T. M. Psicologia do excepcional. São Paulo: EPU, 1986.

ARIÉS, P. História social da criança e da família. Rio de Janeiro: Guanabara, 1981. p.195-280.

ASSIS, S.; AVANCI, J. Q.; PESCE, R.P.; XIMENES, L.F. Situação de crianças e adolescentes brasileiros em relação à saúde mental e à violência. Ciência \& Saúde Coletiva, v. 14, n. 2, p. 349$361,2009$. 
AZEVEDO D.M.; MIRANDA F.A.N.; GAUDÊNCIO M.M.P. Percepções de familiares sobre o portador de sofrimento psíquico institucionalizado. Esc. Anna Nery, Rio de Janeiro, v. 13, n. 3, p. 485-91. 2009.

BARBOSA, C. D. et al. Condutas terapêuticas de atenção às famílias da população infanto-juvenil atendida nos centros de atenção psicossocial infantojuvenis (CAPSi) do estado de São Paulo. Rev. Bras. Crescimento Desenvolvimento Hum, v. 19, n. 2, p. 262-268, 2009.

BARROSO, A. G. C; Abreu L. M; et al. Transtornos Mentais: O Significado para os familiares. Universidade de Fortaleza, 2004. Disponível em: https://www.unifor.br/hp/doc noticias/vol17artigo1.pdf. Acesso em: 01/ setembro/ 2012.

BARROSO, S.M.; BANDEIRA, M.; NASCIMENTO, E. Fatores preditores da sobrecarga subjetiva de familiares de pacientes psiquiátricos atendidos na rede pública de Belo Horizonte, Minas Gerais, Brasil. Cad. Saúde Pública, Rio de Janeiro, v. 25, n. 9, p.1957-1968. 2009.

BELFER M. L. Child and adolescent mental disorders: the magnitude of the problem across the globe. J Child Psychol Psychiatry, v. 49, n. 3, p. 226-36, 2008.

BEZERRA JR. De Médico, de louco todo mundo tem um pouco: o campo psiquiátrico no Brasil nos anos 80. In: GUIMARÃES, Reginaldo; TAVARES, Ricardo A. W. (Org.) Saúde e Sociedade no Brasil: anos 80. Rio de Janeiro, Relume- Dumará, 1994. p. 171-191.

BONI, V.; QUARESMA, S. J. Aprendendo a entrevistar: como fazer entrevistas em Ciências Sociais. Revista Eletrônica dos Pós-Graduandos em Sociologia Política da UFSC, Vol. 2, no 1 (3), janeirojulho/2005, p. 68-80.

BRASIL. Secretaria de Políticas de Saúde. Departamento de Atenção Básica. Programa Saúde da Família. Brasília, São Paulo, v. 34, n. 3, 2000.

Ministério da Saúde do. Relatório final da III Conferência Nacionalde Saúde Mental. Brasília. 2002a.

Ministério da Saúde. Saúde Brasil: uma análise da situação de saúde. 2004.

Id en line Revista de Psicologia. Ano 8, No. 22, Fevereiro/2014 - ISSN 1981-1179. Edição eletrônica em http://idonline.emnuvens.com.br/id 
.Ministério da Saúde. Saúde Mental no SUS: os Centros de Atenção Psicossocial. Brasília, 2004.

Ministério da Saúde. Secretaria Executiva. Legislação em Saúde Mental 1990-2004. $5^{\circ}$ ed. Brasília: Ministério da Saúde, 2004

Ministério da Saúde. Secretaria de Atenção à Saúde. Caminhos para uma política de saúde mental infanto-juvenil. Brasília: Ministério da Saúde, 2005.

. Ministério do Desenvolvimento Social e Combate à fome. Plano nacional de convivência

familiar e comunitária. Secretaria Especial dos Direitos Humanos. Brasília, 2008.

—. Ministério da Saúde. Caps dados atualizados. Disponível em: http://portal.saude.gov.br/portal/arquivos/pdf/caps_dados_atualizadosjulho.pdf Acesso em: 10/ setembro/ 2012

. Ministério da Saúde. Coordenação Nacional de Saúde Mental. Rede Assistencial SUS. Brasília, 2008. Disponível em: http://www.inverso.org.br/index.php/content/view/3160.html. Acesso em: 15/ setembro/ 2012

. Ministério da Saúde, 2002. Portaria $\mathbf{n}^{\circ}$ 336/2002, de 19/02/2002. Brasília: Ministério da Saúde. Disponível em: http://portal.saude.gov.br/portal/arquivos/pdf/Portaria\%20GM\%203362002.pdf. Acesso em: 12/ setembro/ 2012.

Presidência da República. Casa Civil. Subchefia para Assuntos Jurídicos. Lei nº 8.069 da Constituição Federal do Brasil. Brasília, 1990.

CAMPOS, P. H. F; SOARES, C. B.: Representação da sobrecarga familiar e adesão aos serviços alternativos em saúde mental. Psicologia em Revista, Belo Horizonte, v. 11, n. 18, 2005.

CARVAlHO, A. L. L.; AMARANTE, P. Avaliação de Qualidade dos Novos Serviços de Saúde Mental: em Busca de Novos Parâmetros. Saúde em Debate, Londrina, v.52, p.74-78, Setembro, 1996. 
CAVALHERI, S. C. Transformações do modelo assistencial em saúde mental e seu impacto na família. Rev Bras Enferm., n.63, v., p. 51-57, 2010.

CERVENY, C.M.O. Org. Familia e... .São Paulo: Casa do Psicólogo, 2004.

COLVERO, L. de A.; IDE, C. A. C.; ROLIM, M. A. Família e doença mental: a difícil convivência com a diferença. Rev Esc Enferm., v.38, n. 2, p.197-205, 2004.

COLLET N; ROCHA S. M. M. A participação e autonomia a mãe no cuidado ao filho hospitalizado. Rev. Bras. Enf. Brasília (DF), 2003.

COUTO, M. C. V. et al. A saúde mental infantil na Saúde Pública brasileira: situação atual e desafios. Rev. Bras. Psiquiatria, v. 30, n.4, p. 390-8, 2008.

DESVIAT, M. A Reforma Psiquiátrica; Rio de Janeiro: Editora Fiocruz, 1999. 167p.

DIMENSTEIN, M. et al. Estratégia da Atenção Psicossocial e participação da família no cuidado em saúde mental. Physis Revista de Saúde Coletiva, v.20, n. 4, p.1209-1226, 2010.

ERIKSON, E. H. Identidade: Juventude e Crise. Trad: Álvaro Cabral. Rio de Janeiro: Editora Guanabara S.A., 1987.

ESPERIDIÃO, E. Assistência em saúde mental. A inserção da família na assistência psiquiátrica. Revista Eletrônica de Enfermagem (online), Goiânia, v.3, n.1, 2001.

Disponível: http://www.fen.ufg.br/revista

FERREIRA, T. A criança e a saúde mental: enlaces entre a clínica e a política. Ferreira, T. (org). Belo Horizonte: Autêntica/ FCH-FUMEC, 2004.

FLEITLICH-BILYK, B., et al. A saúde mental do jovem brasileiro. São Paulo: Inteligentes, 2004.

FOCAULT, M. O nascimento da clínica. 4 ed. Rio de Janeiro: Forense Universitária, 1994.

FRANCO, B. Escritos Selecionados em Saúde Mental e Reforma Psiquiátrica. Editora Garamond Ltda, Rio de Janeiro, 2005. 
GASPERI, B. L.; MARTINS F. E.; ROSA, R. et al. Mãe e Filho: Os primeiros laços de aproximação. Santa Catarina, 2008.

GIL, A. C. Métodos e Técnicas de Pesquisa Social. 5aed. São Paulo: Atlas, 1999.

Como elaborar projetos de pesquisa. $4^{\circ}$ ed. São Paulo. Atlas. 2002.

GUIMARÃES, T. M. R.; MIRANDA, W. L.; TAVARES, M. M. F. O cotidiano das famílias de crianças e adolescentes portadores de anemia falciforme. Rev. Bras. Hematol. Hemoter., Pernambuco, v. 31, n. 1, p.9-14, 2009.

HAGUETTE, T. M. F. Metodologia qualitativa na sociologia. $3^{\circ}$ Ed. Petrópolis: Vozes, 1992, p.224.

HIRDES, A; NAVARINI, V. A Família do Portador de Transtorno Mental: Identificando Recursos Adaptativos. Rio Grande do Sul, 2005.

IBGE. Instituto Brasileiro de Geografia e Estatística. Censo 2010 > Cidades. Brasília, 2012. Disponível em: http://www.ibge.gov.br/cidadesat/topwindow.htm?1. Acessado em:

IBGE. Instituto Brasileiro de Geografia e Estatística - Cidades. 2012. <http://www.ibge.gov.br>. Acesso em: 23/ janeiro/ 2013.

LEME, L.E.G. A interprofissionalidade e o contexto familiar. In: DUARTE, Y. A. O; DIOGO, M. J. D. Atendimento Domiciliar- um enfoque gerontológico. São Paulo, Atheneu, 2000.

LEOPARDI, M. T. Metodologia da Pesquisa na Saúde. $2^{\circ}$ ed. Florianópolis: Ed. UFSC- Pós Graduação em Enfermagem, 2002.

MELMAN, J. Família e doença mental: repensando a relação entre profissionais de saúde e familiares. São Paulo: Escrituras, 2006.

MINAYO, M. C. S. (Org.) Pesquisa Social: teoria, método e criatividade. $14^{\circ}$ ed. Petrópolis: Vozes, 1999. 
MINAYO, M. C. S. (ORG.) MIRANDA, A. C. (ORG.) Saúde e ambiente sustentável: estreitando nós. Rio de Janeiro: FIOCRUZ, 2002. 341p

MINAYO, M.C.S e cols. Pesquisa Social: Teoria, Método e Criatividade. 25. Ed Petrópolis: Ed. Vozes, 2007.

NAVARINI, V.; HIRDES, A. A família do portador de transtorno mental: identificando recursos adaptativos. Texto \& Contexto Enferm., v. 17, n. 4, p. 680-688, 2008.

OliveirA, A. G. B.; ALESSI, N. P. O Trabalho de Enfermagem em Saúde Mental: Contradições e Potencialidades Atuais. Revista Latino-Americana de Enfermagem, 2003. Disponível em: http://www.scielo.br/pdf/rlae/v11n3/16543.pdf. Acesso em: 20/ agosto/ 2012.

OMS, Organização Mundial de Saúde. Conferência de Caracas. Conferência Regional para a Reestruturação da Atenção Psiquiátrica dentro dos Sistemas Locais de Saúde. Venezuela, 1990. Disponível em: http://pfdc.pgr.mpf.gov.br/atuacao-e-conteudos-de-apoio/legislacao/saudemental/declaracao_caracas. Acesso em: 10/ agosto/ 2012.

PATEL V. et al. Mental health of young people: a global public-health challenge. Lancet, v. 369, n. 9569, p. 1302-13, 2007.

PEGORARO, R.F.; CALDANA, R.H. Sobrecarga de familiares de usuários de um centro de atenção psicossocial. Psicologia em Estudo. 2006.

PEREIRA, M. A. O. Representation of mental illness by the patient's family. Interface -Comunic, Saúde e Educ, v.7, n.12, p.71-82, 2003. Disponível em: http://www.interface.org.br/revista12/artigo1.pdf.

PINTO, R. F. CAPSI para crianças e adolescentes autistas e psicóticos: a contribuição da psicanálise na construção de um dispositivo clínico. Rio de Janeiro, Museu da Republica, 2007. $112 p$.

QUEIROZ, Z. P. V.: Cuidando do Idoso: uma abordagem social. O Mundo da Saúde, V. 24, n. 4, 2000. 
ROSA, L. C. S. A inclusão da família nos projetos terapêuticos dos serviços de saúde mental.

Psicologia em Revista. v. 11, n. 18, p. 205-218, 2005.

REIS, A. O. A. et al. Breve história da saúde mental infantojuvenil. In.: LAURIDSENRIBEIRO, E.; TANAKA, O. Y. (org). Atenção em saúde mental para crianças e adolescentes no SUS. São Paulo: Editora Hucitec, 2010. p.109-130.

RIBEIRO, P. R. M. História da saúde mental infantil: a criança brasileira da colônia à república velha. Psicologia em Estudo, Maringá, v. 11, n. 1, p. 29-38 jan./abr. 2006.

ROMAGNOLI, R. C. O sintoma da família: excesso, sofrimento e defesa. Interações, v.9, n.18, p.4160, 2004.

SALCI M. A; MARCON S. S. De cuidadora a cuidada: quando a mulher vivencia o câncer. Texto e contexto Enferm. Vol 17. nº 03. Florianópolis, 2008.

SAMPAIO, A. B. Saúde Mental e Atenção Psicossocial para infância e adolescência: CAPSi no Município de Iguatu-CE. Curso de Graduação em Enfermagem. Universidade Regional do Cariri. Iguatu, 2008.

SANTOS, D. C. M. Micropolítica do processo de trabalho do enfermeiro e a sua interlocução com o cuidado da equipe de saúde mental com adolescentes. Curso de Mestrado Acadêmico Cuidados Clínicos em Saúde e Enfermagem. Universidade Estadual do Ceará. Fortaleza, 2011.

SILVA, M. B. B. Reforma, responsabilidades e redes: sobre o cuidado em saúde mental. Ciência \& Saúde Coletiva, n.14, v.1, p.149-158, 2009.

SILVA, E. M. Cuidado ao adolescente com transtorno mental no contexto familiar. Curso de Mestrado Acadêmico em Cuidados Clínicos em Saúde e Enfermagem. Universidade Estadual do Ceará. Fortaleza, 2012.

SERAPIONI, M. O papel da família e das redes primárias na reestruturação das políticas sociais. Ciência \& Saúde Coletiva, 10 (sup): 243-253, 2005. 
SCHMID, P. Pensando a rede de saúde mental infanto-juvenil no Rio de Janeiro e os casos graves. In: Ferreira T, organizadora. A criança e a saúde mental: enlaces entre a clínica e a política. Belo Horizonte: Autêntica/FCH-FUMEC; 2004. p. 111- 27.

SCHRANK, G.; OLSCHOWSKY, A. O centro de Atenção Psicossocial e as estratégias para inserção da família. Rev Esc Enferm USP, v. 42, n.1, p.127-134, 2008.

SMELTZER, S. C; BARE, B. G. Tratado de Enfermagem Médico-Cirúrgica. 11. ed, V. 1. Rio de Janeiro: Guanabara Koogan, 2009.

TÁVORA, R. C. O. Típico familiar de crianças e adolescentes em sofrimento psíquico- Reflexões para o cuidado clínico de enfermagem. Curso de Mestrado Acadêmico em Cuidados Clínicos em Saúde e Enfermagem. Universidade Estadual do Ceará. Fortaleza, 2011.

TENÓRIO, F. A Reforma Psiquiátrica Brasileira da Década de 1980 aos Dias Atuais: histórias e conceitos. História, Ciências, Saúde, Manguinhos. Rio de Janeiro, V.9, n.1, p2559, jan/abr, 2002.

TENÓRIO, F. A reforma psiquiátrica brasileira, da década de 1980 aos dias atuais: história e conceitos. História, Ciências, Saúde. Manguinhos, Rio de Janeiro, vol. 9(1):25-59, jan.-abr. 2002. Disponível em: http://www.scielo.br/pdf/hcsm/v9n1/a03v9n1.pdf

Acesso em: 05/ agosto/ 2012.

TOMASI, N.G.; YAMAMOTO, RM. Metodologia da Pesquisa em Saúde; Fundamentos Essenciais. Curitiba; As autoras, 1998, p.98.

TRIVIÑOS, A. N. S. Introdução à pesquisa social em ciências sociais: A pesquisa qualitativa em educação. São Paulo: Atlas, 1992.

VASCONCELOS, E. Do hospício à comunidade. Belo Horizonte, Ed. Segrac. 1992.

WETZEL, C. Avaliação de serviço em saúde mental: a construção de um processo participativo. Tese (Doutorado em Enfermagem Psiquiátrica) Universidade de São Paulo. Escola de Enfermagem de Ribeirão Preto, 2005. 
http://idonline.emnuvens.com.br/id

ISSN on-line: 1981-1179

YASUI, S. CAPS: Estratégia de Produção de Cuidados e de Bons Encontros. In: PINHEIRO, R; GULJOR, A. P.; SILVA JR; GOMES, A. MATTOS, R. A. (Orgs). Desinstitucionalização da saúde Mental: Contribuições para estudos avaliativos. Rio de Janeiro, 2007 p. 155-156.

ZAVASCHI, M.L.S. (org). Crianças e adolescentes vulneráveis: o atendimento interdisciplinar nos centros de atenção psicossocial. Porto Alegre: Artmed, 2009.

\section{Como citar este artigo (Formato ISO):}

OLIVEIRA, N.S.; LIMA, A.B.; ALENCAR, F.S.; OLIVEIRA, G.L.; FREITAS, L.V.T.; ALENCAR, A.V.; OLIVEIRA, G.F. A Vínculo familiar na atenção psicossocial a adolescentes do CAPSI. Id on Line Revista de Psicologia, Fevereiro de 2014, vol.8, n.22, p. 145-181. ISSN 1981-1189.

Recebido: 19/12/2013

Aceito: 03/02/2014 